\title{
An analytical approach to test a thermal management system for Li-ion battery under a real driving condition
}

\author{
Mehdi Mehrabi-Kermani ${ }^{1}$ \\ ${ }^{1}$ School of Mechanical Engineering College of Engineering, University of Tehran, P.O. Box \\ 11155-4563, Tehran, Iran
}

\begin{tabular}{l} 
ARTICLE INFO \\
\hline Keywords: \\
Lithium-ion battery; \\
Hybrid thermal \\
management; Phase \\
change material; Forced \\
convection; Driving cycle \\
mode.
\end{tabular}

\begin{abstract}
A hybrid thermal management system (TMS) for high power lithiumion battery modules of EVs with low energy consumption and high reliability was tested under a real state driving condition. An experimental investigation was performed to compare the hybrid TMS with an active air-cooling and a passive TMSs. We employed all three TMSs in standard weather condition of $24^{\circ} \mathrm{C}$. For dynamic mode, a study of driving cycle in comparison with US, Europe, and Japan driving cycle data was conducted to perform a dynamic model based on a high traffic city to challenge our TMSs in a real driving state including high and standard discharge rate and a stop mode in which there was no air convection. The results showed that just in the hybrid TMS, the cell surface could reach a steady state under $60{ }^{\circ} \mathrm{C}$ while the active TMS could keep temperature only for three cycles. Furthermore, our test proved that the proposed hybrid TMS maintains outstanding reliability and efficiency in the hot weather condition of $40{ }^{\circ} \mathrm{C}$.
\end{abstract}

\section{Introduction}

Due to ever-growing concerns over the environmental pollution, and global warming potential of fossil fuels, the development of various types of clean energy transportation systems is inevitable. Recent developments in Li-ion battery (LIB) technology including higher energy and power density along with lower cost compared to other types of batteries resulted in significant improvements in the electric vehicle (EV) performance, which made the conventional vehicles be confronted with a real challenge in various aspects. The efficiency and performance of LIBs

$\neg$ Corresponding Author E-Mail Address: m.mehrabi2@ut.ac.ir 
directly affect the life cycle and cost of EVs [1]. Therefore, considerable focus is required to keep the battery at its ideal conditions for a longer time. A crucial factor in postponing the battery degradation is controlling the battery temperature. Overheating of LIBs is a critical issue, especially at high discharge rate, which gives substantial rise to the battery capacity fade [2] or thermal runaway [3]. It is suggested that the LIB cell temperature should be kept below the safe temperature of $60^{\circ} \mathrm{C}[4]$ using TMSs. The goal of an efficient TMS is to keep a battery pack at an appropriate average temperature with uniform temperature distribution. Besides, a TMS should be reliable, compatible with a wide range of weather conditions, and low-priced while using low parasitic power [5]. Generally, a TMS is named "active" as a built-in source provides heating or cooling, or "passive" as only the ambient environment is used. Based on the selected media, it can be divided into three major categories: Cooling with air, liquid, or phase change materials. Air is the simplest approach, and air-cooling systems are used for electric vehicles because of cost and space limitations. However, at abuse conditions, especially at high discharge rate and operating temperature, air-cooling will not be a proper option, and the non-uniform distribution of temperature on the surface of the battery cell becomes inevitable. On the contrary, liquid cooling is reliable and shows good performance at stressful conditions. However, pushing a possibly conducting liquid through an electric environment is extremely hazardous while the chamber must be completely sealed. It always proves that liquid cooling systems are costly and more complicated in comparison with air-cooling systems. The PCM was first introduced into the TMS by al-Hallaj and Selman [6]. However, in hot summer days or after several continuous charge and discharge cycles, the PCM may melt completely, and the low thermal conductivity will become a heat transfer barrier. Although some methods such as mixing metal foam, graphite, or nanoparticles have been applied to improve the thermal performance of PCM, this leads to a certain degree of 
latent heat loss. Considering the merits and demerits of each system, the combination of these systems can be very beneficial, which known as hybrid systems.

There are many studies rarely covered all aspects of TMS specifications discussed above. In the current paper, a unique method introduced at our previous work [7] for integrating active and passive components bridged gaps mentioned above is considered to challenge the hybrid TMS in a real driving state. For achieving this purpose, an analytical approach is discussed to enable employing the known dynamometer drive schedules in the world through this hybrid TMS. As the hybrid TMS enjoys advantages of both air active and passive cooling systems simultaneously, not only the test procedure was conducted under normal weather conditions, but also try to challenge it under a hot weather condition which was barely discussed in other studies.

\section{EXPERIMENTAL METHODOLOGY}

\subsection{Preparation and Manufacturing}

A hybrid TMS is comprised of at least an active and passive part. In the present study, for the passive part, commercial paraffin (P 42-44 \#107150) in block form is used as the PCM supplied from the MERCK Company. The other properties are presented in the Table 1. The Copper Foam (CF) with its unique advantage of a skeleton structure, not only growing the strength of the PCM during its melting but also enhance the effective thermal conductivity of PCM. In the current study, Copper foam (CF) with the porosity of $\varepsilon=0.9$ and PPI (pore number per inch) of $\omega=20$ is employed. For the active part, the air is selected as the cooling medium to flow through a copper pinned Heat Sink (HS). The HS is consists of 84 pins, each in length of $14 \mathrm{~mm}$, were cut off from a $2 \pm 0.01 \mathrm{~mm}$ diameter copper rod using a rivet cutter. Two rectangular copper plates as the same size as the sample LIB cell $(93 \times 50 \times 2 \mathrm{~mm})$ is drilled with a regular pattern [8] using Super-Drill and CNC 
Wire-Cut EDM (each hole with a diameter of $1.95 \pm 0.001 \mathrm{~mm}$ ). Afterward, all of the 84 pins were sandwiched under pressure between the two hot copper plates (temperature of $200{ }^{\circ} \mathrm{C}$ ) and brazed with silver rods. Figure 1 shows a picture of the mentioned structures.

Table 1. Properties of PCM

\begin{tabular}{|c|c|}
\hline Parameters & Value \\
\hline Solid density $\left(\mathrm{g} \mathrm{cm}^{-3}\right.$ at $\left.20^{\circ} \mathrm{C}\right)$ & 0.9 \\
\hline Liquid density $\left(\mathrm{g} \mathrm{cm}^{-3}\right.$ at $\left.65^{\circ} \mathrm{C}\right)$ & 0.7 \\
\hline Melting temperature range $\left({ }^{\circ} \mathrm{C}\right)$ & $37.80-44.23$ \\
\hline Latent heat $\left(\mathrm{kJ} \mathrm{kg}^{-1}\right)$ [9] & 249 \\
\hline 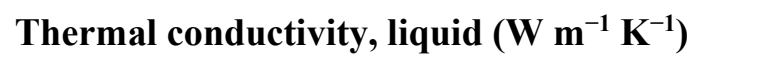 & 0.205 \\
\hline Thermal conductivity, solid ( $\mathrm{W} \mathbf{m}^{-1} \mathrm{~K}^{-1}$ ) & 0.317 \\
\hline Effective thermal conductivity $\left(\mathbf{W} \mathbf{~ m}^{-1} \mathbf{K}^{-1}\right)$ [7] & 11.98 \\
\hline
\end{tabular}
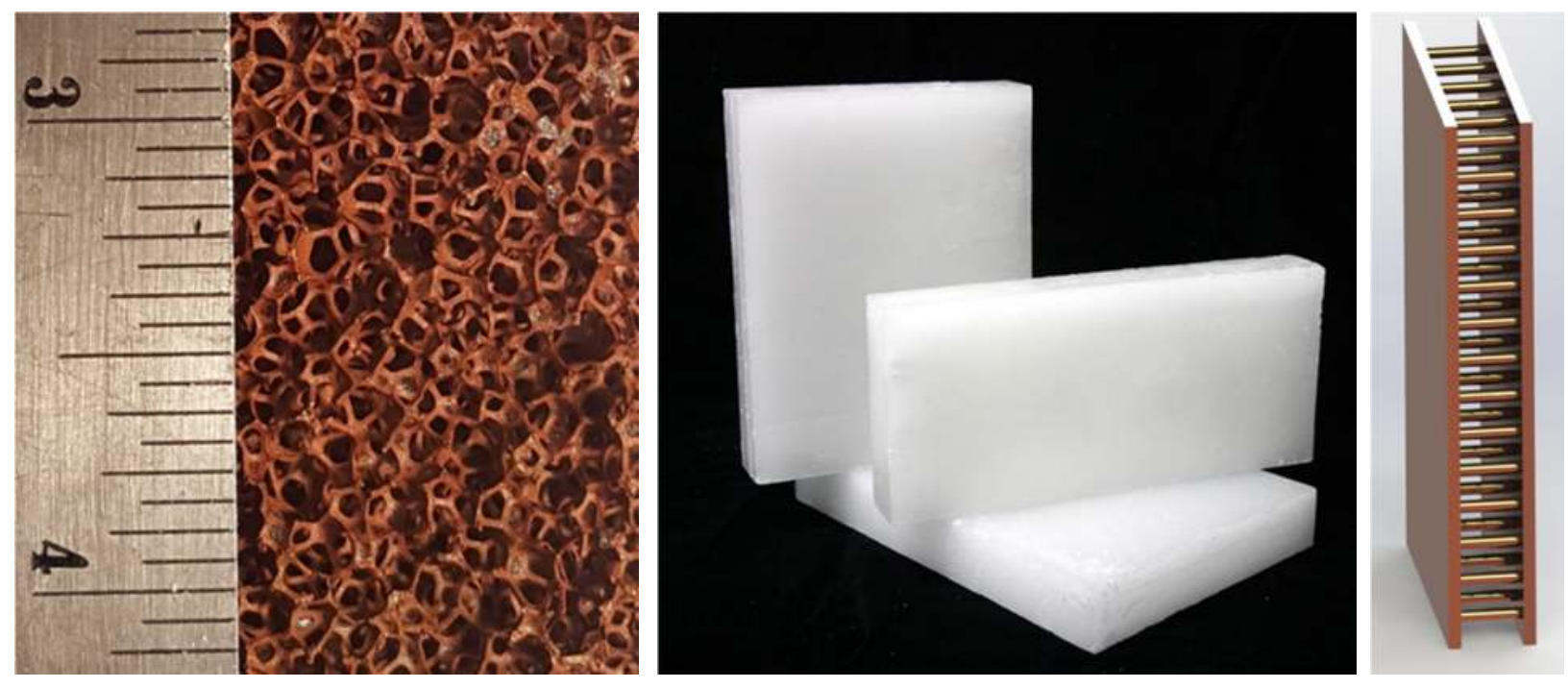

Figure 1. The picture of copper foam, paraffin, and pinned heat sink 
A novel thermal management system for a battery module with $16 \times 3$ large-scale LIB cells is designed (Figure 2-A). The method of combination of the passive and active parts makes this hybrid TMS distinctive. In the passive part, the CF is selected as the thermal conductivity enhancer for the PCM. For active cooling, the heat sink is directly connected to the battery cell surface through the CF. Considering the fact that the $\mathrm{CF}$ is the common part between the two systems, the application will benefit from both systems simultaneously. Fig 2 shows a concept of 16x3 largescale LIB cells sandwiched between passive and active parts. It is assumed that the input air to the entrance of the HS is uniform flow with a constant temperature. The experimental test rig is a detached part of the battery module, which is comprised of two LIB cells and PCM embedded in the CF connected to a HS. More detail of the test setup is mentioned in reference [7]. This paper aims to describe the mechanism of cooling in the hybrid TMS and focused more on the real driving simulation and tests. The method of the combination makes the system enable to take advantages of both the PCM as heat storage for keeping surface temperature uniform in the desired temperature range and the active air-cooling as directly connected to the cell surface for improving the performance of the PCM. Figure 2-B shows the heat transfer mechanism with red arrows. 

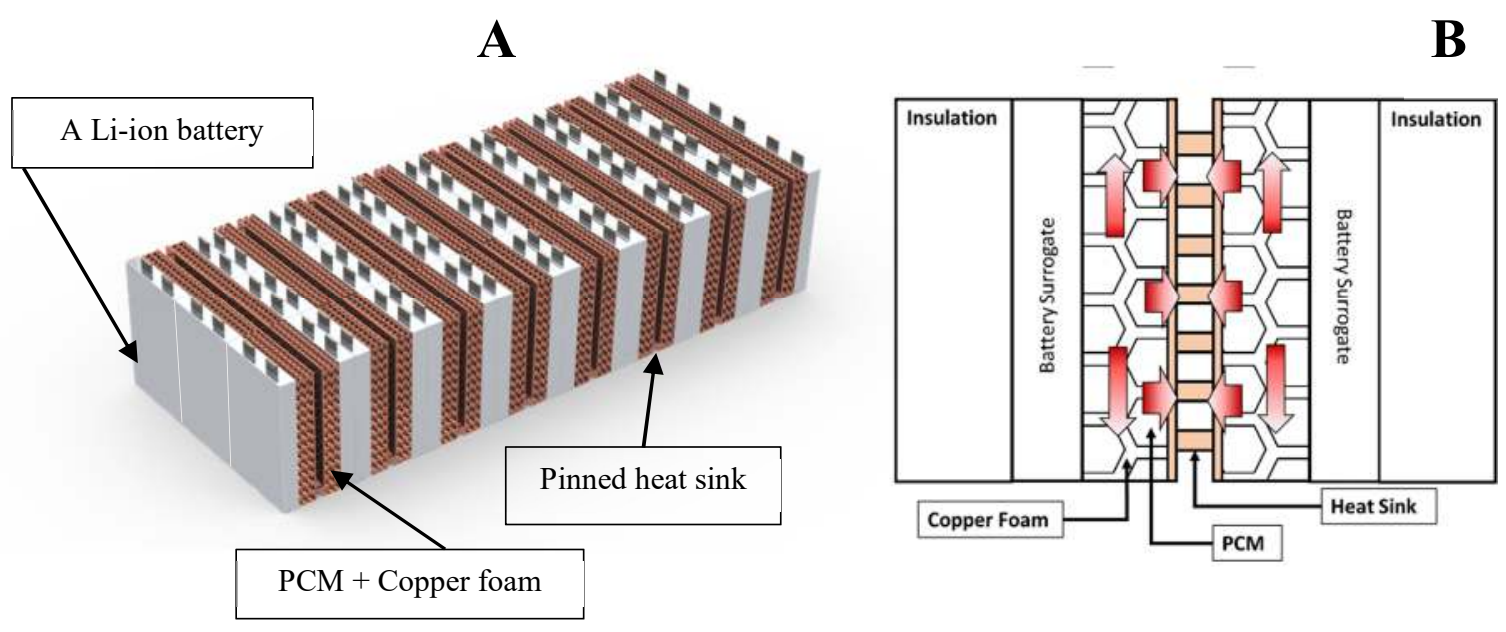

Figure 2.The Li-ion battery module with $3 \times 16$ cells (A) - The mechanism of heat transfer in the hybrid TMS (B) conditions for tests and use film heaters instead of a battery for the safety issues at the thermal runaway (Fig.)

The insulation makes it easy to consider the test setup in symmetry condition and employ film heaters to simulate the heat generated by the battery accurately. The reason for using heater instead of real LIB is safety issues at the thermal runaway. A detailed literature survey [7] was conducted for an ample series of experiments and evaluating abuse conditions of LIBs to obtain temperature produced under natural convection. The approach to the simulation was to find the essential power for the heater in the way to cover all types of LIBs. Finally, 5 and 10 watts was found to emulate the High Constant Current Discharge (HCCD) and the onset of Thermal Runaway (TR) conditions.

\subsection{Analytical Approach}

For the simulation of real driving mode, EV acceleration theory [10] was employed. At the first step, the needed input power was calculated based on known Dynamometer Drive Schedules [11] considering certain EV parameters. After that, a model for heater power was simplified based on 
two heater powers and a stop or regeneration mode which cover all the drive mode data and abused condition may an EV faced in the worst case.

While an EV has a velocity, $\mathrm{v}(\mathrm{m} / \mathrm{s})$, and an acceleration, a $(\mathrm{m} / \mathrm{s} 2)$, the running resistances of the EV include the rolling resistance, $F_{r}(N)$, the acceleration resistance, $F_{a}(N)$, the air resistance, $F_{d}$ $(\mathrm{N})$, and the inclination resistance, $\mathrm{F}_{\mathrm{t}}(\mathrm{N})$. Therefore, the tractive force, $\mathrm{F}(\mathrm{N})$, is determined as the following;

$F=F_{r}+F_{a}+F_{d}+F_{t}(N)$

$F_{r}=m g u$

$F_{a}=m a$

$F_{d}=D v^{2}$

$F_{t}=m g \sin \theta$

where $\mathrm{m}, \mathrm{g}, \mathrm{u}$, and $\mathrm{D}$ are total vehicle weight $(\mathrm{kg})$, gravity acceleration $\left(\mathrm{m} / \mathrm{s}^{2}\right)$, rolling resistance constant, and air resistance constant $(\mathrm{kg} / \mathrm{m})$, respectively. Therefore, the mechanical power consumption, $\mathrm{P}_{\mathrm{m}}(\mathrm{W})$, is expressed by the following equation;

$P_{m}=F \cdot v$

The electrical power consumption, $\mathrm{P}(\mathrm{W})$, is shown in the following equation including total motor efficiency, eff (\%), for a DC motor which the most of losses caused by copper loss for its high current region.

$P=\frac{P_{m}}{e f f}$

Considering the current, I (A), and coil resistance, $\mathrm{r}(\Omega)$, Electrical power consumption can be derived as the following;

$e f f=\frac{P-r I^{2}}{P}$ 
$P=r I^{2}+F v$

Concerning the innate armature, magnetic flux, the radius of the tire, and reduction ratio caused by gear can be considered constant for a certain EV, tractive force is expressed as a function of current.

$F=K I$

Therefore, by assigning (5) to (6);

$P=\frac{r}{K^{2}} F^{2}+F v$

Assuming that the grade resistance is zero, and considering the regenerative power limitation from (1) to (7), electrical power consumption is transformed to:

$P=\frac{r}{K^{2}}\left(D v^{2}+m g u+m a v\right)+v\left(D v^{2}+m g u\right)+m a v$

Given the relation between the acceleration and velocity;

$a=\frac{d v}{d t}=\frac{\Delta v}{\Delta t}$

with the available velocity profile of dynamic driving mode, the electrical power can be calculable. For the EV's parameter to calculate the acceleration velocity, firstly the reference [12] was used and then an upper limit was employed to find the worst situation for electrical power consumption. The figure shows six known Dynamometer Drive Schedules for velocity and corresponding electrical power consumption. 

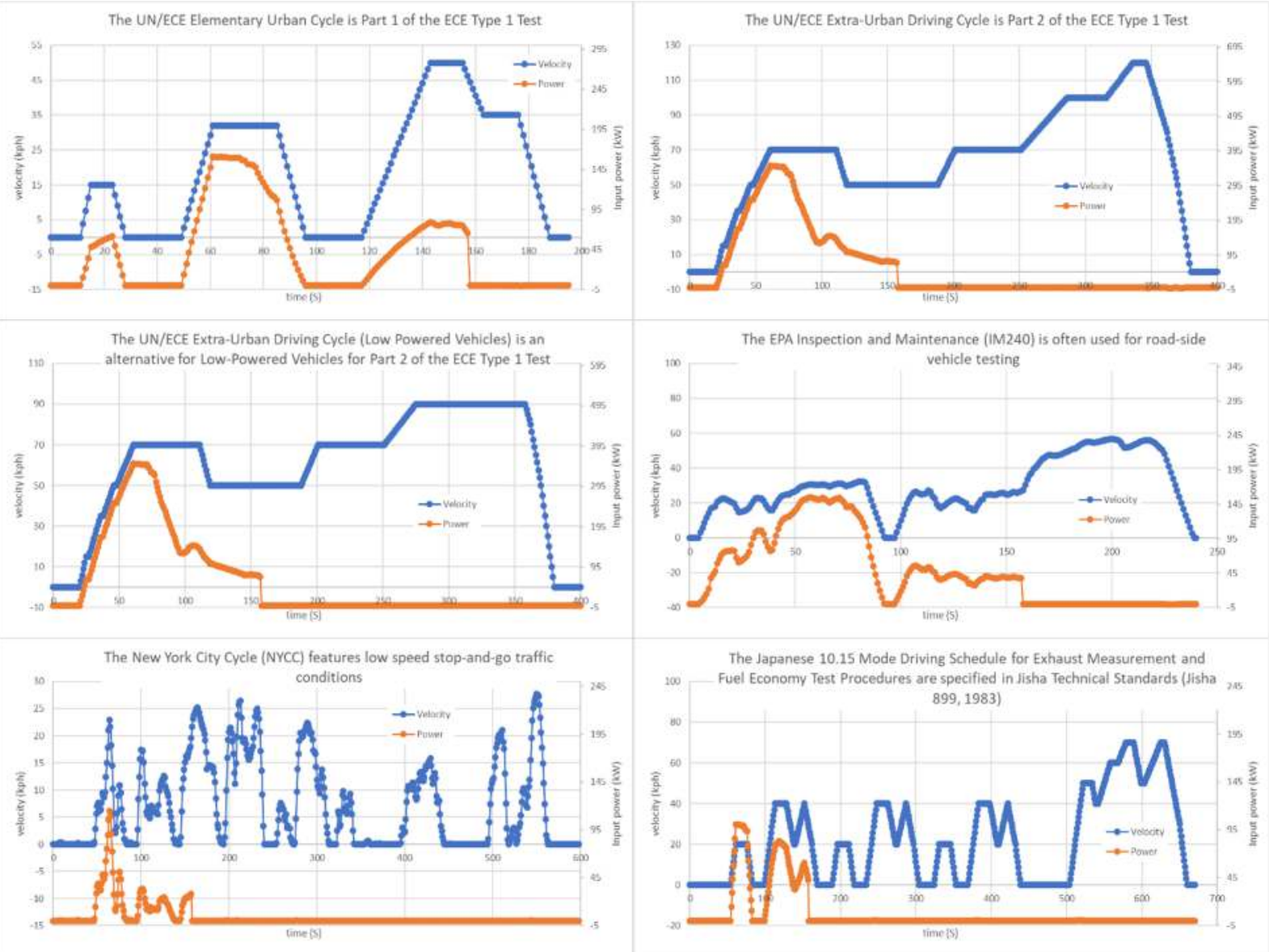

Figure 3. The velocity profile exported from reference [12] and the calculated electrical power consumption

It can accurately be assumed that electrical power consumption is similar to the heat generated by the LIB during the driving mode. The heat generated by LIB was experimentally simulated by film heaters with a wide range of numerical and experimental data. The simulation showed two critical conditions, the HCCD and onset of TR which are more important for LIBs. These two situations were equal to 5 and $10(\mathrm{~W})$ of heater power which can cover the whole situation an EV may be confronted in a real state driving. The mathematical approaches were used to simulate an applicable real driving for high traffic which can be seen at the figure. It is tried to use the maximum acceleration (using more vertical line) to perform a dynamic mode to challenge the 
hybrid TMS in a real driving state including high and standard discharge rate and a stop mode in which there was no air convection. Each cycle was 14 minutes. The tests are continued as long as the temperature exceeds the safe temperature of $60^{\circ} \mathrm{C}$ or reach a steady state at a lower temperature. Figure 4 shows the heater power cycles were employed to heaters in the hybrid TMS.

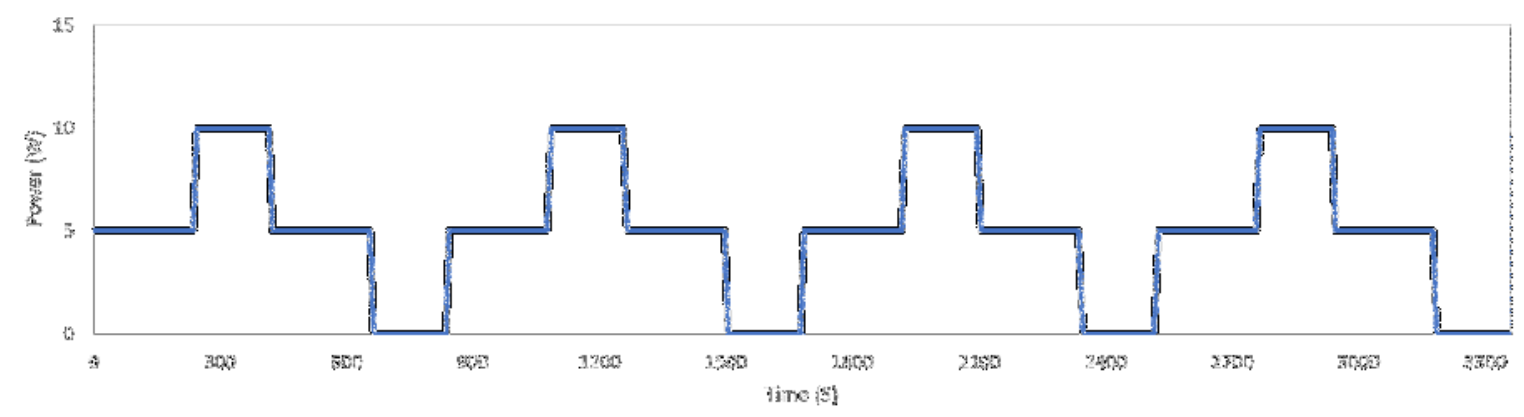

Figure 4. heater power profile employed to surrogated batteries for a real driving state

\section{RESULTS AND DISCUSSION}

The results show (Figure 5) that the passive and active systems could only keep the temperature under $60^{\circ} \mathrm{C}$ just for 1 and 2 cycles, respectively, while the hybrid system reached a steady-state after around 10 cycles and never reached the $60{ }^{\circ} \mathrm{C}$. It shows the power of design of hybrid TMS compared to active and passive TMSs. In the case of hot weather condition (input air to HS was kept at $40^{\circ} \mathrm{C}$ ), only hybrid TMS could keep the temperature for 4 cycles and the other systems ended in total failure at the first cycle. The comparison between systems based on the time each system reached the limit temperature is considerable. The hybrid system compared to the passive and active system could improve the cooling by 91.8 and 89.1 percent, respectively. 

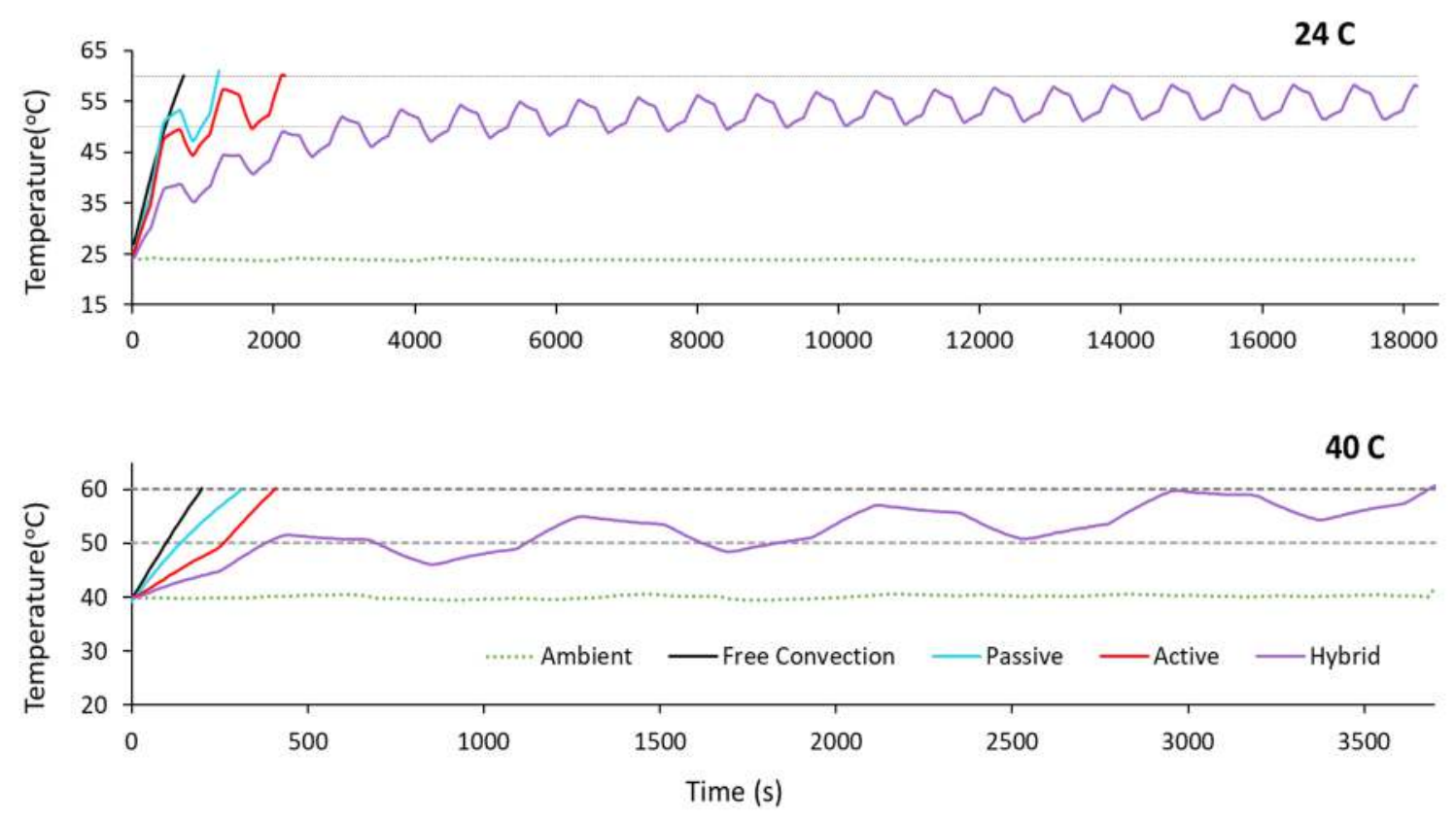

Figure 5. The comparison of active, passive, and hybrid TMSs under the real driving state condition at normal (24 C) and hot weather (40 C) conditions.

\section{CONCLUSION}

It can be concluded that in hot weather and very stressful condition, active, and passive systems have no effective performance and thereby cannot be an appropriate option for a TMS. However, the hybrid system can be an advantageous option in such conditions. The method of combination of passive and active systems play a crucial role.

\section{REFERENCES}

[1] A. Pesaran, A. Vlahinos, T. Stuart, Cooling and preheating of batteries in hybrid electric vehicles, in: 6th ASME-JSME Therm. Eng. Jt. Conf., Citeseer, 2003: pp. 1-7. 
[2] B.S. Haran, P. Ramadass, R.E. White, B.N. Popov, Capacity Fade of Li-ion Cells Cycled at Different Temperatures, in: Proc. Annu. Batter. Conf. Appl. Adv., IEEE, 2002. doi:10.1109/BCAA.2002.986361.

[3] Q. Wang, P. Ping, X. Zhao, G. Chu, J. Sun, C. Chen, Thermal runaway caused fire and explosion of lithium ion battery, J. Power Sources. 208 (2012) 210-224. doi:10.1016/J.JPOWSOUR.2012.02.038.

[4] Väyrynen Antti, Salminen Justin, Lithium ion battery production, J. Chem. Thermodyn. 46 (2012) 80-85. doi:10.1016/J.JCT.2011.09.005.

[5] A.A. Pesaran, Battery thermal management in EV and HEVs: issues and solutions, Batter. Man.

http://www.nrel.gov/vehiclesandfuels/energystorage/pdfs/aabc_lv.pdf.

[6] S. Al Hallaj, J.R. Selman, A novel thermal management system for electric vehicle batteries using phase-change material, J. Electrochem. Soc. 147 (2000) 3231-3236.

[7] M. Mehrabi-Kermani, E. Houshfar, M. Ashjaee, A novel hybrid thermal management for Li-ion batteries using phase change materials embedded in copper foams combined with forced-air convection, Int. J. Therm. Sci. 141 (2019) 47-61. doi:10.1016/j.ijthermalsci.2019.03.026.

[8] A. Al-Damook, N. Kapur, J.L. Summers, H.M. Thompson, An experimental and computational investigation of thermal air flows through perforated pin heat sinks, Appl. Therm. Eng. 89 (2015) 365-376.

[9] M. Akgün, O. Aydın, K. Kaygusuz, Thermal energy storage performance of paraffin in a novel tube-in-shell system, Appl. Therm. Eng. 28 (2008) 405-413. doi:http://dx.doi.org/10.1016/j.applthermaleng.2007.05.013. 
[10] M. Ehsani, Y. Gao, S. Longo, K. Ebrahimi, Modern electric, hybrid electric, and fuel cell vehicles, CRC press, 2018.

[11] Dynamometer Drive Schedules, (n.d.). https://www.epa.gov/vehicle-and-fuel-emissionstesting/dynamometer-drive-schedules.

[12] D. Tanaka, T. Ashida, S. Minami, An analytical method of EV velocity profile determination from the power consumption of electric vehicles, in: 2008 IEEE Veh. Power Propuls. Conf., IEEE, 2008: pp. 1-3.

1. 